\title{
PROJETOS EDUCACIONAIS E POLÍTICAS INTERVENTIVAS NO CAMPO DO PATRIMÔNIO HISTÓRICO, CULTURAL E ARQUEOLÓGICO NA REGIÃO DE ARARAQUARA (SP)
}

\begin{abstract}
Educational projects and interventional policies in the field of historical, cultural and
\end{abstract} archaeological heritage in the region of Araraquara, SP

\author{
Robson Rodrigues ${ }^{1}$ \\ Dulcelaine L. Lopes Nishikawa ${ }^{2}$
}

\section{RESUMO}

A presente comunicação tem por objetivo apresentar aspectos da atuação e do desenvolvimento de programas de preservação do patrimônio histórico, cultural e arqueológico na região de Araraquara (SP). Dentre as ações do grupo de pesquisa GEA/CEIMAM/Fundação Araporã, está a estruturação e a organização de um plano museal para o Museu de Arqueologia e Paleontologia de Araraquara, a criação de um programa educacional continuado, a valorização e afirmação do patrimônio cultural regional e a inserção social. As nossas atividades, a partir do ano de 2008, estruturaram-se na linha de uma proposta de ação educativa voltada para o desenvolvimento da Educação Patrimonial e Ambiental, por meio do Patrimônio Arqueológico Regional. Em nossa perspectiva, ao se dar ênfase em programas educacionais, criamos condições para que a sociedade possa se apropriar do conhecimento arqueológico regional. Acreditamos, ainda, que ao se desenvolver trabalhos nessa perspectiva, criam-se condições para que a sociedade se torne forte parceira na reafirmação dos valores culturais, na promoção de ecossistemas naturais e do desenvolvimento sustentável. Compreendemos que é na salvaguarda do patrimônio cultural, utilizando-se, para tanto, a metodologia da pesquisa-ação e outras abordagens participativas, que poderemos construir um diálogo com as sociedades democráticas, pois é pelo exercício da cidadania que os conhecimentos, as inovações e as práticas são orientadas.

Palavras-chave: Educação Patrimonial, estruturação, Desenvolvimento sustentável

\begin{abstract}
This communication aims to present aspects of the performance and development of programs for the preservation of historical, cultural and archaeological heritage in the region of Araraquara(SP).Among the activities of the research group GEA / CEIMAM / Araporã Foundation, is the structuring and organization of a museal plan to the Museum of Archaeology and Paleontology of Araraquara, the creation of a continued educational program, appreciation and affirmation of regional cultural heritage and social inclusion. Our activities, from the year 2008, were structured along the lines of a proposed educational

\footnotetext{
${ }^{1}$ Doutor em Arqueologia pelo MAE/USP e Pós-Doutor em Antropologia pelo CEIMAM/FCL/UNESP. GEA/CEIMAM/Fundação Araporã. Presidente da Fundação Araporã. robson arqueo@yahoo.com.br

2 Mestre em Engenharia Ambiental pelo CRHEA/USP e Doutora em Sociologia pela FCL/UNESP. GEA/CEIMAM/Fundação Araporã. dulcenishi@yahoo.com.br
} 
activity focused on the development of the Environmental and Heritage Education through the Regional Archaeological Heritage. In our perspective, the emphasizing on educational programs, create conditions for society to appropriate the regional archaeological know ledge. We also believe that developing works in such perspectives, conditions are created, so that society becomes a strong partner in the reaffirmation of cultural values, in the promotion of natural ecosystems and the sustainable development. We understand that it is the safeguarding of cultural heritage, using for this purpose, the methodology of action research and other participatory approaches, we can build a dialogue with democratic societies, it is with the exercise of citizenship that knowledge, innovations and practices are guided.

Keywords: Heritage Education, structuring, Sustainable Development

\section{RESUMEN}

La presente comunicación tiene como objetivo presentar los aspectos de la actuación y del desarrollo de los programas para la preservación del patrimonio histórico, cultural y arqueológico en la región de Araraquara (SP). Entre las acciones del grupo de investigación GEA / CEIMAM / Fundación Araporã, está la estructuración y organización de un plan de museo para el Museo de Arqueología y Paleontología de Araraquara, la creación de un programa de educación continua, la valorización y afirmación del patrimonio cultural $\mathrm{y}$ regional y la inserción social. Nuestras actividades, a partir del año 2008, se han estructurado de acuerdo con una propuesta de acción educativa para el desarrollo de la Educación Patrimonial y Ambiental a través del Patrimonio Arqueológico Regional. Desde nuestra perspectiva, el énfasis en los programas educacionales crea las condiciones para que la sociedad se apropie del conocimiento arqueológico regional. También creemos que el desarrollo de trabajos desde la perspectiva propuesta, se crean las condiciones para que la sociedad se convierta en asociada fuerte en la reafirmación de los valores culturales, en la promoción de los ecosistemas naturales y el desarrollo sostenible. Entendemos que es en la protección del patrimonio cultural, utilizando para ello la metodología de investigaciónacción y otros enfoques participativos, que se puede construir un diálogo con las sociedades democráticas, pues es por las prácticas ciudadanas que los conocimientos, las innovaciones y las prácticas son guiadas.

Palabras clave: Educación Patrimonial, estructuración, desarrollo sostenible

\section{Introdução}

O presente artigo tem por objetivo apresentar aspectos da atuação e do desenvolvimento de programas de preservação do patrimônio histórico, cultural e arqueológico na região de Araraquara, estado de São Paulo. Dentre as ações do Grupo de Estudos Arqueológicos da Fundação Araporã, está a estruturação e a organização de um plano museal para o Museu de Arqueologia e Paleontologia de Araraquara, a criação de um programa educacional continuado, a valorização e afirmação do patrimônio cultural regional e a inserção social. 
O processo de institucionalização do patrimônio arqueológico no município de Araraquara iniciou-se no ano de 1999 com a introdução de ideias a respeito do tema a partir de uma proposta de apoio institucional para projetos científicos na área de Arqueologia, desenvolvidos na região, em conjunto com estudos de impacto ambiental para licenciamento de empreendimentos, numa parceria com o Museu Histórico e Pedagógico "Voluntários da Pátria”. Em síntese, a ideia é a de que todo material seja ele gráfico, textual ou de objetos, resultante do trabalho de campo de arqueólogos, fique sob a guarda do Museu que atesta os endossos para pesquisa junto ao Instituto do Patrimônio Histórico e Artístico Nacional (IPHAN), órgão do Ministério da Cultura responsável pela preservação do patrimônio cultural brasileiro.

Ao longo deste período e a partir de inserções junto ao poder público local e sociedade, as propostas de projetos estruturais na área de Arqueologia avançaram. Vários espaços públicos de diálogo com a comunidade local e organizados no município foram sendo ocupados.

Seminários e semanas de discussão sobre o patrimônio cultural, criação da coordenadoria de patrimônio histórico no contexto da Secretaria de Cultura, audiências públicas para estruturação do Plano Diretor, onde foram definidas as áreas de interesse arqueológico e paleontológico, introdução do tema na criação do Conselho Municipal de Preservação do Patrimônio Histórico e Cultural do Município de Araraquara, são alguns exemplos que contaram com a inserção do tema arqueológico em suas reflexões.

Entendemos que a parceria com o gestor federal de preservação do patrimônio, o IPHAN e instituições voltadas à preservação do patrimônio arqueológico e estruturadas no âmbito municipal permitem maior controle da comunidade local, na preservação de seu patrimônio, já que possibilita um envolvimento direto dos interesses individuais com os temas abordados coletivamente, facilitando assim, a mobilização de diferentes segmentos organizados no município.

A partir da sensibilização da municipalidade, aprovação do projeto estrutural pelo governo federal e efetivação do repasse de recursos para a prefeitura municipal de Araraquara, foram constituídos os dois espaços físicos para a salvaguarda, preservação, conservação, restauro, pesquisa dos acervos patrimoniais e destinados às atividades ligadas ao desenvolvimento da Arqueologia brasileira, tendo sido inaugurados no final de 2008.

O primeiro espaço se trata de um museu municipal denominado Museu de Arqueologia e Paleontologia de Araraquara (MAPA) e que se localiza no centro da cidade. Este espaço está diretamente ligado à história de Araraquara, na medida em que após um 
projeto de revitalização e modernização arquitetônica do antigo conservatório musical do maestro José Tescari, construção da década de 1880, passou a integrar o complexo de museus do município.

Em suas dependências conta com os ambientes da reserva técnica para abrigar o acervo arqueológico, composto por peças cerâmicas, material lítico, material ósseo, adornos corporais, entre outros e o acervo paleontológico, composto por lajes areníticas e fósseis com vestígios de diversos animais e insetos; laboratório para análise de coleções; área de exposição permanente e temporária; sala para apresentações diversas com recurso multimídia, setor administrativo e espaços de apoio aos visitantes.

Apesar de ter sido inaugurado em 2008, somente em 28 de novembro de 2011 foi promulgada a Lei $\mathrm{n}^{0}$. 7.575 instituindo o MAPA como uma unidade museológica subordinada à Secretaria Municipal de Cultura, por meio da Coordenadoria Executiva do Patrimônio Histórico e Cultural e dando outras providências.

Durante as oficinas participativas realizadas para construção do Plano Museal para o museu ficou definido como missão e os valores que:

\begin{abstract}
O Museu de Arqueologia e Paleontologia de Araraquara (MAPA) tem como missão realizar pesquisas de excelência nas áreas de Arqueologia, Paleontologia e Museologia. Sediado no município de Araraquara, o MAPA tem como território de intervenção o interior paulista, configurando-se em um pólo de construção de conhecimento, formação e preservação do patrimônio. Inserido em uma região caracterizada por vestígios arqueológicos e paleontológicos significativos, mas que ainda carece de instituições que abordem esse patrimônio de forma dinâmica e contemporânea, o MAPA tem importante papel na descentralização das pesquisas científicas no estado de São Paulo. Organizado com base no tripé "pesquisa, ensino e extensão", o museu assume objetivos intrinsecamente relacionados à sua função social: preservar os vestígios arqueológicos e paleontológicos do interior paulista para as futuras gerações, promover o uso qualificado desse patrimônio, socializar o conhecimento disponível acerca do patrimônio cultural regional e possibilitar oportunidades de aprendizado para estudantes nas áreas de Arqueologia, Paleontologia e Museologia (RELATÓRIO DA OFICINA, 2011).
\end{abstract}

O segundo espaço destinado à Arqueologia e ao patrimônio histórico cultural é o Centro de Conservação e Recuperação de Acervos Diversos (CECRAD). Este espaço foi idealizado para o desenvolvimento de ações de conservação e preservação de acervos patrimoniais e, como o MAPA, também teve a aprovação da lei de criação, anos após sua inauguração.

Neste sentido, o CECRAD foi instituído pela Lei $n^{\circ} .7 .732$ de 24 de maio de 2012 como uma unidade laboratorial subordinada à Gerência de Museus da Secretaria Municipal de Cultura. Este espaço foi idealizado para o desenvolvimento de ações de conservação, triagem, 
curadoria, restauro e preservação de acervos patrimoniais. Em suas dependências conta com ambientes para reserva técnica, laboratório para análise de coleções, sala de processamento de dados, depósito de materiais, ferramentas, reserva técnica temporária, espaço para limpeza e higienização dos acervos.

Entendemos, no entanto, que, apenas a existência de um espaço físico, não garante uma relação de valorização do patrimônio cultural regional, especialmente no que compete à Arqueologia. Sendo assim, entre os nossos desafios está a construção de um museu que tenha como princípio a inserção da questão indígena: não de forma generalizante, mas como parte constituinte de um processo histórico do interior paulista.

Ao proceder a uma avaliação mais ampla do cenário social local, entendemos que o MAPA cumpre com sua missão, pois consegue se comunicar com a sociedade local. No entanto, no que compete a função social ainda estamos num processo de construção que tem sido feita dentro de princípios norteadores da sociomuseologia.

A partir dessa perspectiva, busca-se a adequação das estruturas museológicas a partir da compreensão de que existe uma diversidade social e que é preciso se comunicar com diferentes grupos sociais. Os museus, na perspectiva da sociomuseologia, devem ter maior interação social, o que garante outra dinâmica dos espaços museais em relação à comunidade envolvente. A busca pela sociomuselogia se dá pelo fato de acreditarmos que os espaços do museu têm que assumir um caráter multidisciplinar e principalmente consolidar os museus como estruturas sustentáveis; tanto no âmbito social, quanto econômico, garantindo assim, igualdade de oportunidades e de inclusão social.

Concordamos com Lisboa e Müller (2011) quando afirmam que o mero fato de o museu abrir suas portas por um determinado período do dia, não dá conta de justificar sua despesa que na maioria das vezes não garante o seu caráter público. Já os programas educacionais criam essa aproximação. Ações educativas conferem valor não só ao próprio museu, como também potencializam as obras pertencentes ao acervo, dando vazão ao caráter conhecido dentro das teorias da restauração como sendo o ato metodológico do reconhecimento da obra ou do objeto, na sua consistência física e na sua dúplice polaridade: estética e histórica.

Segundo os autores supracitados, a instituição museológica detém sob sua tutela e responsabilidade um determinado conjunto de acervos museológicos, que devem estar disponíveis a toda comunidade, por intermédio de estratégias de acessibilidade e espaços que proporcionem interação das obras com a população em geral, além disso, ações educativas serão necessárias para a sociabilização dos acervos perante os grupos sociais envolvidos. 
A nossa proposta é a de que o Museu de Arqueologia e Paleontologia de Araraquara promova a interação com os diferentes grupos da sociedade, sempre pautado no tempo atual, ou seja, procurar referenciar o presente, visando à construção coletiva de uma perspectiva de futuro. Cientes do fato de que essa relação precisa ser construída de forma horizontalizada, passamos a buscar o fortalecimento do espaço museal a partir de programas educacionais que possibilitem a sensibilização dos munícipes. A aposta nessa perspectiva se dá porque compreendemos que só assim haverá uma real valorização dos bens patrimoniais. Os cidadãos ao reconhecerem os bens materiais, imateriais e ambientais, como parte da identidade coletiva, passam a contribuir para o aprimoramento da gestão do patrimônio local, pois os reivindicam como parte daquilo que pertence a sua cultura. As ações educativas se apresentam como sendo de fundamental importância, pois consolidam uma ação social que reflete nas políticas públicas de preservação em desenvolvimento no país.

\section{A Concepção de Educação patrimonial no âmbito do MAPA}

O Programa de Educação que está sendo desenvolvido no Museu de Arqueologia e Paleontologia de Araraquara pela Fundação Araporã tem fortalecido a relação com o patrimônio histórico, cultural e arqueológico regional, pois procura dialogar com a sociedade envolvente, na medida em que traz ao conhecimento do público a existência de uma Arqueologia na região, rompendo com a ideia de que é necessário ir a lugares longínquos para saber e vivenciar uma experiência arqueológica, pois este fazer arqueológico está presente no cotidiano social local.

Desde o início dos trabalhos a busca se deu pela criação de uma relação de identidade com a cultura existente na região. Para isso, focamos as ações com os grupos educacionais, formais e não formais, e na inserção social como um todo.

O carro chefe para as ações educativas são os sítios arqueológicos, pois são espaços que oferecem elementos para a construção do conhecimento tanto no que diz respeito aos aspectos da cultura material, quanto imaterial e também ambiental, dando elementos para ampla reflexão a respeito de como se constrói uma pesquisa científica.

Dentre as possibilidades de análise podemos ressaltar, por exemplo, escolha da área para implantação dos sítios arqueológicos, pois, por meio dessa ideia, podemos entender os motivos de caráter ambiental utilizados pelos seres humanos no passado para realizarem suas escolhas, pois estes locais evidenciam aspectos de uso, ocupação e transformação dessas áreas no que cabem aos aspectos físicos, bióticos e socioeconômicos. 
O que temos observado é que esses espaços tem se apresentado como profícuos do ponto de vista educacional, pois apresentam uma multiplicidade de conhecimentos e também permitem uma análise transversal, possibilitando uma efetiva construção de identidade sociocultural com esses materiais arqueológicos encontrados na região, adicionando diferentes elementos na compreensão da história pré-colonial que rompam com os estereótipos ou ideias construídas erroneamente sobre as populações indígenas, tanto no que compete à relação homem-natureza, quanto à concepção de que essas populações não teriam evoluído. Colocando em evidência essa temática no cotidiano da educação, entendemos ser possível construir uma memória regional das populações indígenas e perceber as suas contribuições para a sociedade atual.

Temos observado que o conhecimento adquirido por meio dos vestígios arqueológicos, quando trabalhado de forma adequada, pode fazer com que o patrimônio arqueológico passe a ser reconhecido pela população como parte de sua identidade e, consequentemente, valorizado, podendo gerar desdobramentos preservacionistas.

Entre nossos objetivos está principalmente a apropriação cidadã dos bens patrimoniais, para que assim, estes cidadãos possam efetivamente ter o livre acesso aos diversos contextos e conhecimentos gerados a respeito da produção cultural e ambiental existentes no âmbito regional.

O ser humano, enquanto produtor de cultura, precisa entender que faz parte de um universo mais amplo e a sua produção cultural está diretamente relacionada à forma com a qual ele construiu sua relação com a natureza na sua trajetória histórica, ou seja, desde períodos pré-coloniais até o presente momento.

Para atingir esses objetivos educacionais no âmbito museal, nos apoiamos na sociomuseologia e na pesquisa-ação, pois são possibilidades analíticas e metodológicas que permitem uma interação com as bases comunitárias. Temos, portanto, na perspectiva educacional, um estimulador de ações e de conscientização patrimonial embasado nos objetos culturais, pois esses são fragmentos de memória e trazem traços de momentos de gerações passadas que poderão ser utilizados para dinamizar as atividades educacionais propostas.

Ao se pensar uma proposta de Educação Patrimonial no contexto museológico é preciso ter clareza de que a construção de uma identidade sociocultural com o passado só será possível se estimularmos a imaginação do público acerca de outras épocas e identificar as formas de se pensar as situações sociais existentes. Para atingir esse objetivo, no entanto, é preciso respeitar as particularidades do Patrimônio histórico cultural de cada localidade. Sendo assim, um eixo de sustentação para a formação dessa identidade é promover a interação 
entre história, memória e cultura, para que as informações e os objetos possam ser ressignificados.

Entendemos, tal como Le Goff (2003), que a História não é a ciência do passado. Considerá-la passado é um absurdo e observar o passado como objeto desta ciência também o é. Na concepção do autor, a História é a ciência dos homens no tempo, onde as relações do passado e do presente são tecidas em meio a valores ao longo da história.

O autor supracitado considera também que a História não só permite compreender o presente pelo passado (atitude tradicional), mas também compreender o passado pelo presente, perspectiva esta vantajosa, segundo o autor, pois o passado é uma construção e uma reinterpretação constante e também o futuro é parte integrante e significativa da história. Assim, se confirma resolutamente o caráter científico e abstrato do trabalho histórico, não aceitando que seja creditado somente à cronologia.

Diante da importância da visão histórica e qual o seu papel na construção da identidade sociocultural, fica visível um importante desafio: como desenvolver uma proposta de museologia que seja atenta à necessidade de comunicação com a sociedade e a transforme?

Para Leite (2011) ao citar Moussouri (2007), o desafio passa pela necessidade dos educadores de museus tornarem as experiências museais mais memoráveis. A acessibilidade das coleções/exposições e a capacidade dos museus delinearem e cumprirem suas missões (seu foco) deve ser revisada, para que este, enquanto instituição, seja capaz de compreender seu papel eminentemente social e educacional.

Sendo assim, esta perspectiva pressupõe novos métodos didáticos de aprendizado, como a utilização de maneiras ativas que colocam o público no centro da ação pedagógica, contribuindo, assim, para o desenvolvimento, construção progressiva e durável do sentimento de pertencimento e valorização do patrimônio cultural.

Leite (2011) explica, ainda, que Moussouri considera que os desafios correntes passam por perceber a natureza do aprendizado que emerge das experiências museais: como elas ocorrem, como se desenvolvem e, portanto, como podem ser otimizadas. Baseada na teoria de aprendizagem sociocultural de Vygotsky, ao afirmar que as pessoas aprendem umas com as outras, mais do que individualmente, por isso o foco dos museus deve ser o de se instituir como lócus de aprendizagem. Portanto, sabe-se que o que as pessoas aprendem em museus não é o ponto chave, mas sim como se dá esse aprendizado.

Para Moussouri (2007, apud LEITE, 2011), o espectador, no museu, independente da temática do mesmo, vive fundamentalmente uma experiência de constituição identitária a partir do reconhecimento e/ou estranhamento daquilo que é visto. Nesse aspecto, 
apresentando sempre a diversidade étnica e cultural que compõe nossa sociedade, este processo estimula o conhecimento e rompe com os preconceitos, pois permite que os indivíduos passem a respeitar a diversidade existente no nosso entorno.

Aqui, é importante comentar, também, que em nosso processo educacional temos trabalhado com oficinas lúdicas na construção de novas propostas educativas. O motivo para tal escolha se dá pelo fato de que as oficinas se apresentam como facilitadoras da assimilação dos conhecimentos abstratos por meio de ações mais concretas.

Segundo Maurício (2008) a ludicidade é importante no processo ensinoaprendizagem. O "brincar" como um processo facilitador da aprendizagem gera uma melhoria no desenvolvimento humano no que tange ao crescimento pessoal, social, cultural e motor, além da comunicação, expressão e construção de pensamento quando as ações educativas são acompanhadas de oficinas lúdicas.

Esta situação ocorre porque o ato de brincar e jogar torna o indivíduo capaz de pensar, imaginar, interpretar e criar, aspectos estes, que propiciam autonomia, iniciativa, concentração e análise crítica para levantar hipóteses acerca dos fatos, bem como nos ensinam a respeitar regras e vivenciar conflitos competitivos. Maurício (2008) menciona ainda que a ludicidade reflete a expressão mais genuína do ser; é o espaço de todo ser para o exercício da relação afetiva com o mundo, com as pessoas e objetos. Por meio das atividades lúdicas, o indivíduo forma conceitos, seleciona ideias, estabelece relações lógicas, integra percepções e se socializa.

A ligação das atividades lúdicas com a aprendizagem proporciona o estabelecimento de relações cognitivas, simbólicas e produções culturais. O lúdico possui dois fatores motivacionais, o prazer e o ambiente espontâneo. As tarefas lúdicas demandam um interesse intrínseco do indivíduo, pois este canaliza sua energia para cumprir com os objetivos propostos, produzindo um sentimento eufórico e de entusiasmo.

Dallabona e Mendes (2004), ainda comentam que as atividades lúdicas são peçaschave para desenvolver a solidariedade e empatia, como também, para introduzir novos conceitos para a posse e para o consumo. Em nossa atuação educativa, diagnosticamos essa possibilidade quando desenvolvemos as oficinas. Observamos que elas são facilitadores na obtenção da anuência dos públicos, independente da faixa etária e tem sido um forte aliado na construção de um diálogo promissor acerca do patrimônio histórico, cultural e arqueológico. A questão ambiental também tem se apresentado como um elemento fundamental nas nossas ações, pois age como um elemento de interação. 
Consideramos que o ser humano é um ser de ação e relação e não pode ser percebido fora de suas relações com os outros e com o mundo. Entendemos que ele é capaz de se transformar e de transformar a sua realidade. Dentro desta visão, a característica metodológica inerente aos processos pedagógicos para a abordagem da Educação Patrimonial e Ambiental está baseada principalmente na participação. Participar se aprende exercendo o direito da cidadania e o exercício desse direito se dá nas mais variadas formas e níveis.

Sendo assim, ao propormos o desenvolvimento das oficinas de Educação Patrimonial e Ambiental por meio da valorização dos aspectos da cultura indígena, por exemplo, não partimos de uma visão idílica de que esses sujeitos não impactam a natureza. Contudo, entendemos que vivem em interação com a mesma devido à necessidade de preservar e manter a sua própria existência. Este processo acontece pelo fato de se ter uma ideia de que é necessário preservar e manejar as áreas ambientais em que vivem. Esse é um dos princípios básicos da ecologia: a inter-relação. Quando temos a percepção de que somos parte da natureza, podemos nos considerar sensibilizados e conscientes do nosso papel educacional de sermos multiplicadores.

A tarefa educacional esta associada à da redescoberta dos valores pessoais e da busca de novas concepções que tornem a sociedade humana mais justa e solidária. Assim sendo, um dos principais objetivos da Educação Patrimonial e Ambiental desenvolvidos por nós (RODRIGUES e NISHIKAWA, 2012) consiste em permitir que as pessoas compreendam as complexas relações que se encontram no meio ambiente e os resultados desfavoráveis ao próprio ser humano, fruto de suas intervenções. O que se espera é que essa ação educativa leve à promoção de uma ação reflexiva e prudente acerca dos aspectos culturais e ambientais, favorecendo a construção de uma participação responsável nas decisões de melhoria da qualidade do meio natural, social e cultural.

Nosso pressuposto teórico ao desenvolver ações educativas está pautado na teoria filosófica de Paulo Freire (1997). O autor defende a ideia de que a educação está associada a uma forma de ler o mundo. E nesse mundo todos os sujeitos produzem conhecimento e, portanto, geram cultura. Sendo assim, a educação não é a mera reprodução do conhecimento. Para o autor a educação é um ato político.

Este processo de construção educacional tem que ser coletivo como afirmamos ao longo deste texto, pois como bem define Freire (1987), não se deve fazer uma política cultural, sem conceber como estratégia todos os sujeitos envolvidos. O conceito de educação popular consiste em um esforço de mobilização, organização e capacitação dos sujeitos (FREIRE, 1970/1987). E acreditamos que esse também deva ser o papel do arqueólogo- 
educador. Para Paulo Freire "era preciso ler o mundo para poder transformá-lo" (apud, GADOTTI, 2002). Por esta razão, sua teoria passa por uma visão crítica e não pela mera reprodução técnica. Perpassa pela idéia de que é preciso valorizar o conhecimento dos sujeitos, assim como a sua produção cultural. E isso possibilitará uma relação de pertencimento e identidade com os bens patrimoniais e culturais e a consciência de seus direitos, como sua inserção crítica na realidade.

$\mathrm{Na}$ medida em que os sujeitos vão se organizando, produzem uma forma cada vez mais justa de pensar. Este sistema se dá por meio da problematização de seu mundo e da análise crítica de sua prática, que possibilitará aos sujeitos da ação atuar cada vez mais seguramente no mundo, contribuindo, assim, para que estes se assumam como seres do seu fazer, ou seja, que desenvolvem uma práxis. Vale dizer que, como sujeitos, ao transformar o mundo com seu trabalho, criam um novo mundo. Este, elaborado pela transformação do anterior, se constitui em algo de seu domínio. É o mundo da cultura que se prolonga no mundo da história (FREIRE, 1997).

Entre os princípios filosóficos de Freire, está a utilização de temas geradores e conteúdos programáticos que possibilitem entender e discutir as relações homens-mundo (FREIRE, 1987). Entendemos que a proposta do autor se adequa a nossa prática pedagógica, pois utilizamos a construção material da cultura, e definida pela Arqueologia, para entendimento das diferentes sociedades. Este sistema nos possibilita melhor compreensão da materialidade, pois fornece elementos para a compreensão do ser humano enquanto produtor de cultura. Essa criação e recriação da cultura se dá em interação com a natureza por meio do trabalho, ou seja, da sua produção material na transformação do meio. Nesse sentido, propomos a compreensão da relação do homem na natureza e com a natureza, por meio da cultura material, rompendo com uma visão dicotômica de compreensão para se transformar em uma visão dialética.

Ao propor essa reflexão espera-se atingir um primeiro conceito, o mais básico de todos na humanidade: o da produção de cultura por meio do trabalho. Essa produção está diretamente associada à subsistência, pois, desde os primórdios do surgimento e desenvolvimento do homem na terra, este tema se constitui como fundamental para a própria existência humana.

Nesse sentido, passamos a explorar a ação da produção humana não só como uma necessidade, mas também como uma construção do conhecimento do homem em relação à natureza. Entendemos que é na natureza que o homem explora as possibilidades das matérias primas para solucionar as suas necessidades primárias, mas, ao desenvolver as condições 
objetivas para descobrir e criar, aprimorando, assim, a sua produção do conhecimento, gera um conjunto de elementos diversificados que identificamos como sendo a produção cultural de um determinado grupo social humano.

O entendimento de que uma rocha é melhor para lascar do que a outra, de que o barro existente próximo à cabeceira de um determinado rio é melhor para fazer a cerâmica, segundo Freire (1989), é possível de acontecer porque o homem em relação com o mundo, fez desse pensar a base para a construção do seu conhecimento, submetendo-se, portanto, por meio do trabalho, a um processo de transformação constante. Ou seja, ao manusear as matérias primas oriundas da natureza, confeccionou sua roupa, seus utensílios, seus instrumentos de trabalho, de caça, de coleta e de pesca.

Paulo Freire (1989) propõe de maneira simples, mas objetiva, que essa relação não pode ser de dominação do homem pelo homem, mas sim, uma relação entre sujeitos da ação. Igualmente responsáveis e cooperadores entre si; e não só entre si, mas também, com a natureza. Quando pensamos a Educação Patrimonial esse deve ser um princípio presente nas nossas ações, pois o que se pretende é romper com a concepção de que as sociedades précoloniais são inferiores a nossa. E que a produção da cultura material e simbólica dessa sociedade seja incipiente. Portanto, essa ação permite mostrar às pessoas de uma maneira geral que a produção material por meio do trabalho existiu desde as sociedades pré-coloniais, com os mesmos objetivos que nós temos hoje quando pensamos a produção de materiais para a nossa comodidade.

A nossa perspectiva é interdisciplinar, pois compreendemos que para se desenvolver uma proposta de Educação Patrimonial que avalie também elementos da Educação Ambiental (RODRIGUES e NISHIKAWA, 2012) só é possível por meio de uma compreensão dos diversos campos do conhecimento. Nesse sentido, fazemos a leitura à luz de algumas áreas do conhecimento da Arqueologia da Paisagem, a partir dos estudos de Morais (2000), que nos auxilia na compreensão das questões ambientais. E no que compete aos aspectos da Educação Patrimonial a referência é o trabalho desenvolvido por Bezerra (2002).

A Arqueologia da paisagem vai introduzir no debate arqueológico fatores que serão de fundamental importância, pois trazem informações importantes no que correspondem às escolhas para as implantações dos sítios arqueológicos, evidenciando uma complexidade a ser analisada já que permite agregar uma valorização ambiental aos sítios arqueológicos, trazendo um apontamento para os estudiosos de meio ambiente a observação dos aspectos intrassítios em associação com os aspectos inter-sítios. 
Essa leitura é importante à medida que torna possível entender que mesmo entre as populações pretéritas à escolha dessas ou daquelas áreas para a implantação de seus aldeamentos eram definidos por características físicas, bióticas e geográficas que melhor se adaptassem às necessidades do grupo. Esse procedimento de escolha do uso e ocupação do espaço confirma a relação primeira entre homem-natureza.

O conhecimento adquirido por intermédio da informação histórica, antropológica, geográfica e ambiental pode proporcionar aos educadores e alunos a ampliação de seu universo do saber à medida que proporciona o entendimento de como eram estabelecidas as relações que os indivíduos tinham com o Meio Ambiente, evidenciando a possibilidade de uma ação educativa não só no que compete aos aspectos do meio, mas também no que compete ao reconhecimento da necessidade de preservação do patrimônio arqueológico, no entendimento de que há necessidade de se construir uma identidade associando sociedade, meio ambiente e patrimônio arqueológico.

\section{Considerações Finais}

Na perspectiva apresentada, ao darmos ênfase nos programas educacionais, criamos condições para que a sociedade possa se apropriar do conhecimento arqueológico regional. Acreditamos, ainda, que ao se desenvolver trabalhos nessa perspectiva, criam-se condições para que a sociedade se torne forte parceira na reafirmação dos valores culturais, na promoção de ecossistemas naturais e do desenvolvimento sustentável. Compreendemos que é na salvaguarda do patrimônio cultural, utilizando-se, para tanto, a metodologia da pesquisa-ação e outras abordagens participativas, que poderemos construir um diálogo com as sociedades democráticas, pois é pelo exercício da cidadania que os conhecimentos, as inovações e as práticas são orientadas.

A concepção que aqui defendemos é a de que a ação do educador patrimonial perpassa por uma visão crítica e o arqueólogo que se pretende educador precisa desenvolver ao mesmo tempo a pesquisa arqueológica associada a um comprometimento com a sociedade, nunca perdendo de vista que o objetivo é proporcionar aos diversos públicos, múltiplos olhares acerca da história das populações humanas que habitaram a região.

Entre os princípios norteadores da nossa ação está o de tornar o espaço do museu um local que a sociedade se sinta representada, pois ao desenvolvermos ações educativas no âmbito do museu, concomitantemente, nossa intervenção procura trazer os grupos envolvidos como coprodutores dos resultados apresentados nos trabalhos expostos. Nesse sentido, 
acreditamos que essa prática pode fortalecer uma relação de pertencimento com o espaço museal e criar uma identidade com os bens patrimoniais existentes no local.

Temos como resultados bons indicadores e opiniões dos públicos envolvidos, que avaliam positivamente o desenvolvimento das atividades educativas como tendo a possibilidade de compreensão dos conteúdos apresentados nas exposições de longa duração nas áreas de Arqueologia e Paleontologia do Museu de Arqueologia e Paleontologia de Araraquara.

Nesse sentido, estamos trabalhando para proporcionar uma vivência educacional diferente da educação “bancária”, como define Freire (1987), na construção de possibilidade dos educandos realizarem uma interpretação dos conteúdos e não uma simples assimilação ou absorção.

\section{Referências bibliográficas}

BEZERRA, M, de A, 2003. O australopiteco corcunda. As crianças e a Arqueologia em um Projeto de Arqueologia Pública na Escola. TESE defendida, na Universidade de São Paulo, Programa de Pós-Graduação em Arqueologia MAE/USP-SP: 180 p.

DALLABONA, Sandra Regina. MENDES, Sueli Maria Schimitt. O lúdico na educação infantil: jogar, brincar, uma forma de educador. In: Revista de divulgação técnico-científica Vol. 1 n. 4 - jan.-mar./2004. Disponível em: http://www.icpg.com.br/artigos/rev04-16.pdf acessado em jan.2013. Acessado em 02/01/2013

FREIRE, P. A. Ação cultural para a liberdade e outros escritos. $5^{\mathrm{a}}$ ed., Rio de Janeiro, Paz e Terra. $1981.149 \mathrm{p}$.

2000.

Pedagogia da Indignação: cartas pedagógicas e outros escritos, Ed. Da UNESP, . Pedagogia do Oprimido. $17^{\mathrm{a}}$ Ed. Rio de Janeiro, Paz e Terra, 1987.

. Pedagogia Educação e Mudança. Tradução de Moacir Gadotti e Lilian Martin, Rio de Janeiro: $18^{\mathrm{a}} \mathrm{ed}$. Paz e terra, 1979.

. Educação Como Prática da Liberdade. Rio de Janeiro, Paz e Terra, 1967 (19 ed., 1989).

GADOTTI, M. Pedagogia da terra. Editora Peirópolis, São Paulo 2002.

LE GOFF, J. (2003). História e memória. Campinas, SP: Ed. UNICAMP.

LEITE, Maria Isabel. Museus e público infantil - alguns casos e várias reflexões. Revista eletrônica EducaMuseu, ano I, nº1-agosto de 2011. 
LEITE, Nívea. O ensino da Pré-História nas escolas de 1 o e 20 graus. IN: KERN, Arno Alvarez. ANAIS, 8a Reunião científica da SAB - Sociedade de Arqueologia Brasileira. Porto Alegre: EDIPUCRS, 1996.

LUPORINI, T.J. "Lugares da memória” no Estado do Paraná: demandas e políticas pela preservação do patrimônio cultural. $\quad$ Disponível http://www.revistas2.uepg.br/index.php/olhardeprofessor/article/view/1340/984 Acesso em dez. de 2012.

LISBOA, P.F, MÜLLER, M, C. A educação patrimonial como projeto de desenvolvimento regional no pampa rio-grandense. Disponível em $<\mathrm{http}: / / \mathrm{www} . p a b l o l i s b o a . c o m / a r t i g o-$ EDUCACAO-Patrimonial-LISBOA-maio2011.pdf >. Acesso em 02/02/2013.

MAURICIO, Juliana Tavares. Aprender brincando: o lúdico na aprendizagem. 2008. Disponível em: http://www.pedagogia.com.br/artigos/importanciadabrinquedoteca1/index.php?pagina=9. Acessado em 05/02/2013.

MORAES WICHERS, C. A. Patrimônio Arqueológico Paulista: proposições e provocações museológicas. Tese de doutorado apresentada ao programa de Pós-graduação do Museu de Arqueologia e Etnologia da Universidade de São Paulo, SP, 2011.

MORAIS, J. L, 2000. Tópicos de arqueologia da paisagem. Revista do Museu de Arqueologia, Universidade de São Paulo- no. 10, ISSN 0103-9709. 03-30.

RODRIGUES, R e NISHIKAWA, D. L. L. Reflexões a respeito da educação patrimonial e ambiental a partir da arqueologia desenvolvida na região de Araraquara/SP. Disponível em http://www.ambiente-augm.ufscar.br/uploads/A3-093.pdf Acesso, 20/10/2012. Acessado em $10 / 02 / 2013$. 